\title{
Formation of Carbon Nanomaterials Having the Brittle Star-Like Mophology
}

\author{
Gi-Hwan Kang, Sung-Hoon Kim* \\ Department of Engineering in Energy and Applied Chemistry/Silla University \\ 140 Baegyang-daero, 700beon-gil, Sasang-gu, Busan 617-736, Korea \\ nice_gyan@naver.com; shkim@silla.ac.kr
}

\begin{abstract}
The carbon nanomaterails having the brittle star-like morphology (bs- $\mathrm{CNMs}_{\text {) }}$ could be synthesized using $\mathrm{C}_{2} \mathrm{H}_{2}-\mathrm{SF}_{6} \mathrm{gases}$ under thermal chemical vapour deposition (TCVD) system. The micro-sized Ni grains were used as the catalyst for bs-CNMs on the $\mathrm{Al}_{2} \mathrm{O}_{3}$ substrate. The bs-CNMs could be obtained under the condition of the source gases flow rates at $100 \mathrm{sccm}$ for $\mathrm{C}_{2} \mathrm{H}_{2}$ and $50 \mathrm{sccm}$ for $\mathrm{SF}_{6}$. The bs-CNMs were understood to be composed of the numerous carbon nanofibers sprayed out from the central Ni grain. During the deposition reaction of the bs-CNMs, the central Ni grain seemed to move upward, while the sprayed-carbon nanofibers, in several thread strand types, seemed to go on downward. Most of the bs-CNMs were vertically grown onto the surface of the substrate. At the long time reaction (after 20 minutes), the bs-CNMs developed into the untangled thread bundles.
\end{abstract}

Keywords: Carbon Nanomaterials, Brittle Star-like Morphology, Growth Mode, Chemical Vapour Deposition,

\section{Introduction}

Recently many researchers have noticed the diverse forms of the carbon nanomaterials, such as tubes, fibers, graphenes, horns, onions, helices, and so on [1-4]. The diversity in the morphology of the carbon nanomaterials may extend the practical application areas using the morphology-correlated properties. Therefore, the synthesis of the carbon nanomaterials having the unique morphologies is a primary initial step to develop the morphology-correlated materials properties. Among the various unique-shaped carbon nanomaterials, the one dimensional carbon nanomaterials (1D-CNMs), like the carbon nanotubes, were noticed as the good support for the high performance catalyst of the chemical reaction [57]. Indeed, they can enhance the performance of the catalyst because they can hold the numerous metal catalysts which have the size as small as possible. Namely, the decrease in the size of the metal catalyst can increase the surface area of the metal catalyst, consequently enhancing the active area for the catalyst role. In the case of the alcohol oxidation of the direct alcohol fuel cells 1D-CNMs were known to be act as the noble hosting geometry for the metal catalyst particles but also the protector from the degradation by the carbon monoxide poisoning $[8,9]$.

In this work we present the method to fabricate the brittle star-like morphology of carbon nanomaterials (bs-CNMs) as the unique-shaped 1D-CNMs. To produce this morphology, we used bunch-type Ni clusters on the $\mathrm{Al}_{2} \mathrm{O}_{3}$ substrate and injected $\mathrm{C}_{2} \mathrm{H}_{2}$ and $\mathrm{SF}_{6}$ gases under the thermal chemical vapor deposition system. The characteristics of the as-grown carbon nanomaterials were investigated as functions of the gas flow rates of $\mathrm{C}_{2} \mathrm{H}_{2}$ and $\mathrm{SF}_{6}$ and the reaction times. Based on the closer investigation on the initiation point of the numerous carbon nanofibers from the metal catalyst, the detailed morphology and the developing aspect of the bs-CNMs was proposed and discussed.

\section{Experimental}

The $2.0 \times 2.0 \mathrm{~cm}^{2}$ alumina $\left(\mathrm{Al}_{2} \mathrm{O}_{3}\right)$ plates having the $2 \mathrm{~mm}$ thickness were used as the substrate in this work. For the Ni catalyst preparation, approximately $0.01 \mathrm{~g}$ of $\mathrm{Ni}$ powder $(99.7 \%)$ with particle diameters ranging from 100 to $200 \mu \mathrm{m}$ was spread onto the substrate. Thermal chemical vapor deposition (TCVD) system was employed with $\mathrm{C}_{2} \mathrm{H}_{2}$ and $\mathrm{SF}_{6}$ as the source gases. Substrate temperature and total pressure in the reactor were constantly maintained at $750^{\circ} \mathrm{C}$ and $100 \mathrm{Torr}$, respectively. The flow for $\mathrm{C}_{2} \mathrm{H}_{2}$ was varied from 50 to 500 standard $\mathrm{cm}^{3}$ per minute $(\mathrm{sccm})$ and the flow of $\mathrm{SF}_{6}$ was set at $50 \mathrm{sccm}$. The detailed deposition reaction conditions for the formation of the various carbon structures are shown in Table 1. The eight study samples used different flows of the source gases and/or different deposition reaction times (Table 1). 
Detailed morphologies and chemical compositions of the samples were investigated using field emission scanning electron microscope (FESEM, Hitachi S-4200). Ni chemical composition in the catalyst was analyzed using Energy Dispersive X-ray Spectroscopy (EDS).

Table 1: Experimental conditions for the formation of the bs-CNMs on the substrates.

\begin{tabular}{c|cccccc}
\hline Sample & $\begin{array}{c}\mathrm{C}_{2} \mathbf{H}_{2} \text { flow } \\
\text { rate } \\
(\mathbf{s c c m})\end{array}$ & $\begin{array}{c}\mathrm{SF}_{6} \text { flow } \\
\text { rate } \\
(\mathbf{s c c m})\end{array}$ & $\begin{array}{c}\text { Total } \\
\text { pressure } \\
(\text { Torr) }\end{array}$ & $\begin{array}{c}\text { Deposition } \\
\text { Time(min) }\end{array}$ & Ni size $(\mu \mathrm{m})$ & $\begin{array}{c}\text { Substrate } \\
\text { temp. } \\
\left({ }^{\circ} \mathrm{C}\right)\end{array}$ \\
\hline A & 50 & 50 & 100 & 60 & $100-200$ & 750 \\
\hline B & 100 & 50 & 100 & 60 & $100-200$ & 750 \\
\hline C & 150 & 50 & 100 & 60 & $100-200$ & 750 \\
\hline D & 250 & 50 & 100 & 60 & $100-200$ & 750 \\
\hline E & 100 & 50 & 100 & 5 & $100-200$ & 750 \\
\hline F & 100 & 50 & 100 & 10 & $100-200$ & 750 \\
\hline G & 100 & 50 & 100 & 20 & $100-200$ & 750 \\
\hline H & 100 & 50 & 100 & 40 & $100-200$ & 750 \\
\hline
\end{tabular}

\section{Results and Discussion}

First of all, the surface morphologies of the as-grown carbon nanomaterials were investigated as a function of the gas flow rate ratio of $\mathrm{C}_{2} \mathrm{H}_{2} / \mathrm{SF}_{6}$. As show in Fig 1a, the lowest flow rate ratio of $\mathrm{C}_{2} \mathrm{H}_{2} / \mathrm{SF}_{6}$ in this work gave rise to the formation of the small-sized (smaller than $1 \mu \mathrm{m}$ ) grains and the well-faceted large-sized (bigger than $1 \mu \mathrm{m}$ ) grains. The small grains were regarded as the carbon embryos and the large one was thought to be the Ni catalyst with the absorbed carbon elements. With increasing the flow rate ratio of $\mathrm{C}_{2} \mathrm{H}_{2} / \mathrm{SF}_{6}$ from 1 to 2 , the untangled thread bundles could be observed as shown in Fig. 1b. With more increasing flow rate ratio of $\mathrm{C}_{2} \mathrm{H}_{2} / \mathrm{SF}_{6}$ from 2 to 3 , the thread bundles having the thick thickness were developed onto the substrate surface (see Fig. 1c). At the highest flow rate ratio, namely $5, \mathrm{of}_{2} \mathrm{C}_{2} \mathrm{H}_{2} / \mathrm{SF}_{6}$ in this work, we could observe the conventional carbon microcoils as shown in Fig. 1d. These results reveal that the conventional carbon microcoils could be formed under the flow rate ratio of $\mathrm{C}_{2} \mathrm{H}_{2} / \mathrm{SF}_{6}$ more than 3 . We are interested in the results under the flow rate ratio of $\mathrm{C}_{2} \mathrm{H}_{2} / \mathrm{SF}_{6}$ less than 3. In particular, the research in this work was focused on the formation results of the carbon nanomaterials at 2 of the flow rate ratio of $\mathrm{C}_{2} \mathrm{H}_{2} / \mathrm{SF}_{6}$.
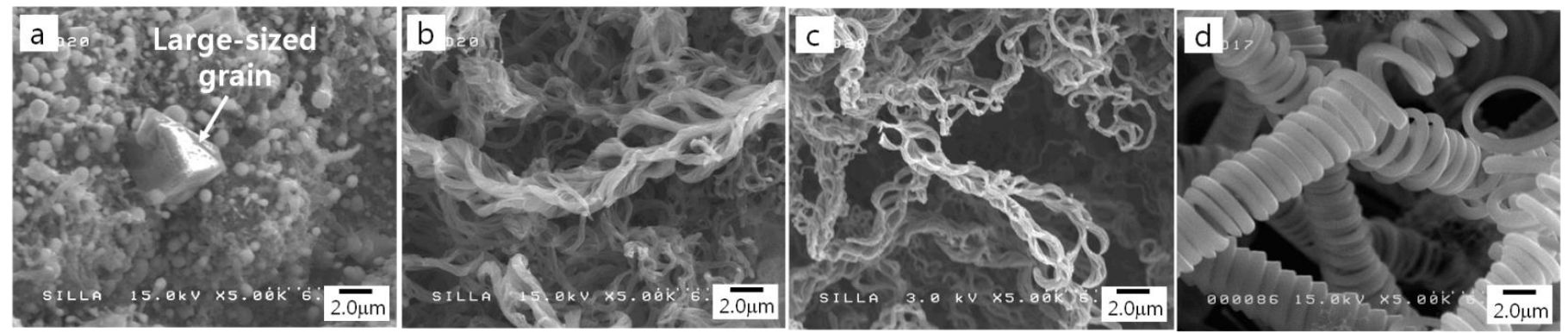

Fig. 1: FESEM images of the surface morphologies of (a) sample $A\left(\mathrm{C}_{2} \mathrm{H}_{2} / \mathrm{SF}_{6}\right.$ flow rate ratio $\left.=1\right)$, (b) sample $B\left(\mathrm{C}_{2} \mathrm{H}_{2} / \mathrm{SF}_{6}\right.$ flow rate ratio = 3), (c) sample $\mathrm{C}\left(\mathrm{C}_{2} \mathrm{H}_{2} / \mathrm{SF}_{6}\right.$ flow rate ratio $\left.=5\right)$, and (d) sample $\mathrm{D}\left(\mathrm{C}_{2} \mathrm{H}_{2} / \mathrm{SF}_{6}\right.$ flow rate ratio $\left.=10\right)$.

Figures $2 \mathrm{a}-2 \mathrm{~d}$ show FESEM images of the surface morphologies for sample $\mathrm{B}$ with the different deposition reaction times, namely 5 (sample E), 10 (sample F), 20 (sample G) and 40 minutes (sample H), respectively. For sample E, at 5 minutes deposition reaction times, we observed that the circular type grains were spread onto the surface of the substrate (see Fig. 2a). The circular type grains have the various sizes in diameters. From the EDS spectrum result shown in Fig. 3, these 
grains were confirmed to be the Ni catalysts. After 10 minutes deposition reaction times (sample F), the numerous carbon nanofibers were appeared and they were sprayed out from the circular type $\mathrm{Ni}$ grains. Indeed these circular type $\mathrm{Ni}$ grains were located around the central position of the sprayed-out carbon nanofibers. The morphology including the central $\mathrm{Ni}$ grains and the numerous carbon nanofibers sprayed out from the Ni grains was named as the brittle star-like morphology in this work.

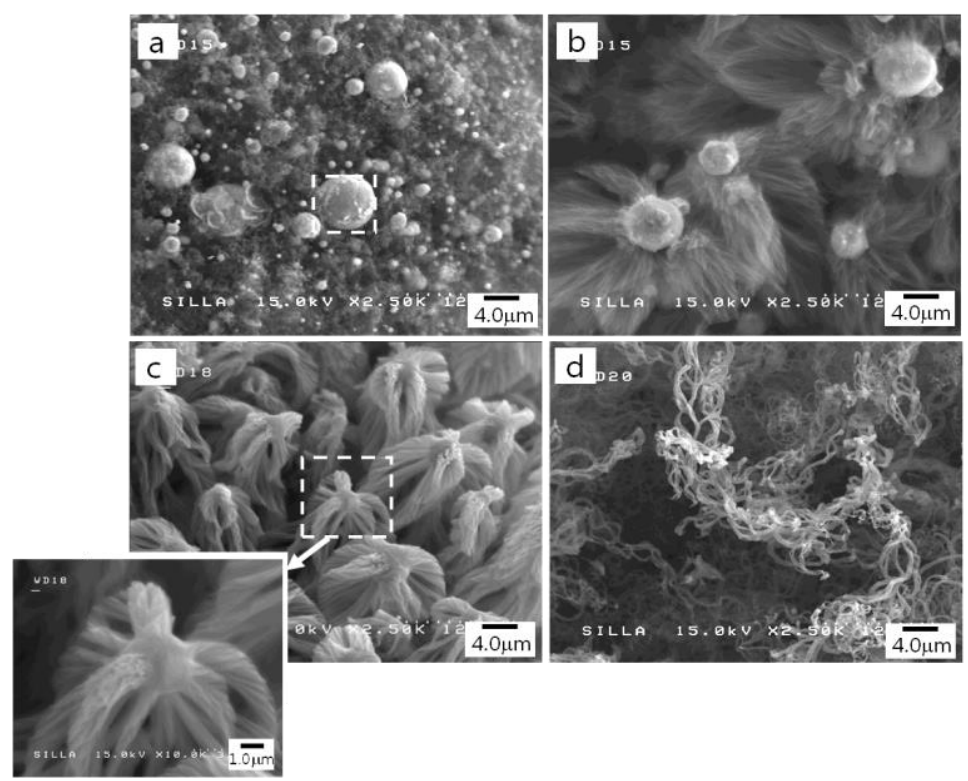

Fig. 2: FESEM images of the surface morphologies of (a) sample E, (b) sample F, (c) sample G, and (d) sample H.

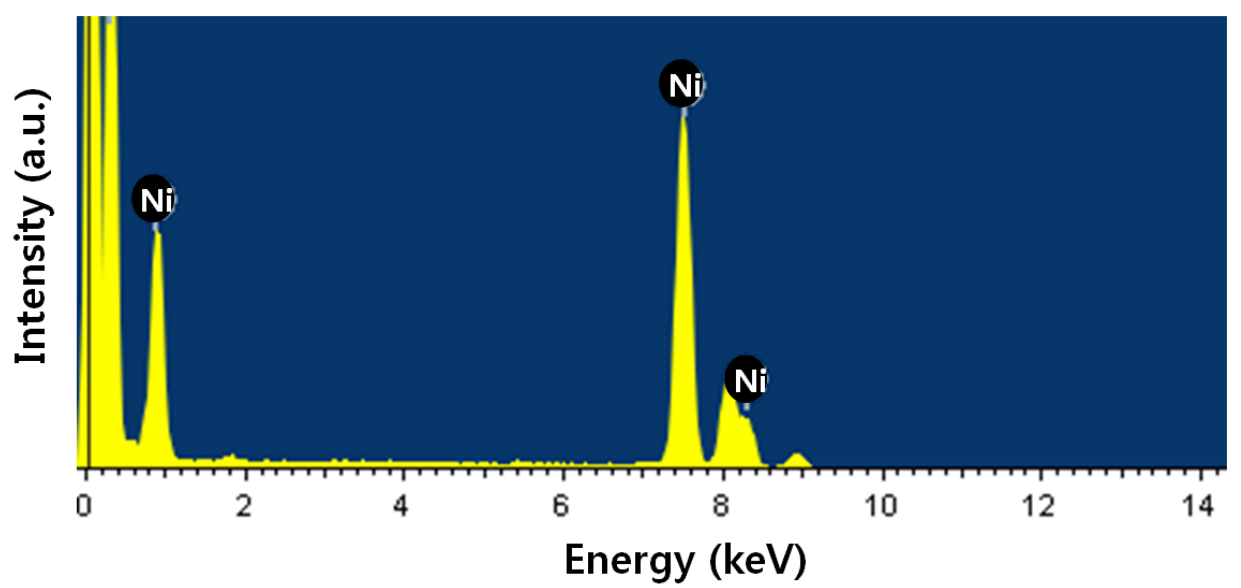

Fig. 3: EDS spectrum for $\mathrm{Ni}$ in the area enclosed by the square in Figure 2a.

With increasing the deposition reaction time up to 20min (sample G), the brittle star-like morphology seemed to be more developed and eventually formed the bs-CNMs on the whole surface of the sample. In the bs-CNMs, the central Ni grain seemed to move upward, while the sprayed-carbon nanofibers, in several thread bundle types, seemed to go on downward as shown in the magnified image of the dotted-square in Fig. 2c (see the inset in Fig. 2c). Interestingly, most of the bs-CNMs were seemed to be vertically grown onto the surface of the substrate. Indeed, we could achieve the large scale dominant growth of the bs-CNMs following the vertical direction onto the surface of the substrate as shown in Fig. 4. This dominant vertical growth of the bs-CNMs was understood to be used in the diverse application area, such as field emitter, micro-mechanical shock moderator, and so on. At longest deposition reaction time (40 min, sample $\mathrm{H}$ ), we observed the untangled multiple bundles having a lot of thread strands on the surface of the substrate as shown in Fig. 2d. From the results of Figs. 2, we suggest that the reaction time of $20 \mathrm{~min}$ is the optimal reaction time condition for the formation of the bs-CNMs although the exact reaction time would be dependent on the experimental situation. 


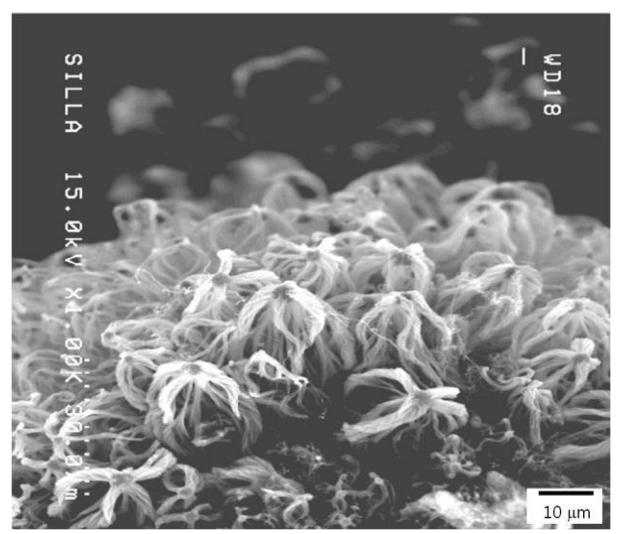

Fig. 4: Low magnified-image of sample G. Most of the bs-CNMs were vertically grown onto the surface of the substrate

\section{Conclusion}

We could achieve the vertical growth of the unique brittle star-like morphology of the carbon nanomaterials under the condition of the source gases flow rate at $100 \mathrm{sccm}$ for $\mathrm{C}_{2} \mathrm{H}_{2}$ and $50 \mathrm{sccm}$ for $\mathrm{SF}_{6}$. This morphology was composed of the numerous carbon nanofibers sprayed out from the central Ni grain. In addition, the central Ni grain was located at the upper position and the sprayed-carbon nanofibers, in several thread strand types, was spread to the downward direction. At the longest deposition time $(40 \mathrm{~min})$ in this work, the vertically-grown bs-CNMs developed into untangled multiple bundles having a lot of thread strands. The reaction time of $20 \mathrm{~min}$ is suggested as the optimal reaction time condition for the formation of the bs-CNMs.

\section{Acknowledgements}

This work was supported by the Human Resource Training Program for Regional Innovation and Creativity through the Ministry of Education and National Research Foundation of Korea (2014 H1C1A1066859).

\section{References}

[1] J. M. Ting and W. C. Lin, "Unprecedented re-growth of carbon nanotubes on in situ re-activated catalyst," Nanotechnology, vol. 20, pp. 025608, 2009.

[2] A. K. Geim and K. S. Novoselov, "The rise of grapheme," Nat. Mater., vol. 6, pp. 183-191, 2007.

[3] Z. L. Tsakadze, I. Levchenko, K. Ostrikov, and S. Xu, "Plasma-assisted self-organized growth of uniform carbon nanocone arrays," Carbon, vol. 45, pp. 2022-2030, 2007.

[4] D. Fejes and K. Herna'di, "A review of the properties and CVD synthesis of coiled carbon nanotubes," Materials, vol. 3, pp. 2618- 2642, 2010.

[5] C. W. Xu, L. Q. Cheng, P. K. Shen, and Y. L. Liu, "Methanol and ethanol electrooxidation on Pt and Pd supported on carbon microspheres in alkaline media," Electrochemistry Communications, vol. 9, pp. 997- 1001, 2007.

[6] D. S. Yuan, S. Z. Tan, Y. L. Liu, J. H. Zeng, and F. P. Hu, "Pt supported on highly graphitized lace-like carbon for methanol electrooxidation," Carbon, vol. 46, pp. 351-536, 2008.

[7] E. Antolini, "Carbon supports for low-temperature fuel cell catalysts," Appl. Catal. B, vol. 88, pp. 1-24, 2009.

[8] V. Hacker, E. Wallnofer, W. Baumgartner, T. Schaffer, J. O. Besenhard, and H. Schrottner, "Carbon nanofiber-based active layers for fuel cell cathodes - preparation and characterization," Electrochemistry Communications, vol. 7, pp. 377-382, 2005.

[9] C. C. Chien and K. T. Jeng, "Effective preparation of carbon nanotube-supported Pt-Ru electrocatalysts," Mater. Chem. Phys., vol. 99, pp. 80-87, 2006. 